\title{
ECOS DA MEMÓRIA E DA RESISTÊNCIA ESTUDANTIS: $O$ PODER JOVEM DE ARTHUR POERNER CINQUENTA ANOS DEPOIS
}

Thiago Bicudo Castro ${ }^{1}$

RESUMO: O livro O Poder Jovem e seu autor Arthur Poerner estiveram no centro dos debates sobre a resistência cultural e política à ditadura civil-militar instaurada em 1964. Tanto o autor quanto a obra podem ser interpretados a partir dos eventos políticos iniciados com a assinatura do Ato Institucional $n^{\circ} 2$ de 1965 até 1968 e a publicação do Ato Institucional $n^{\circ} 5$. Arthur Poerner teve seus direitos políticos cassados em razão do AI-2 e o livro O Poder Jovem foi lançado em 1968 e imediatamente censurado. Este livro, desde o lançamento até suas reedições nas décadas seguintes, teve uma importante influência no movimento estudantil, sendo, inclusive, um meio de reconstrução da memória deste movimento e da UNE. Este artigo analisa a forma como Poerner fomentou a criação de um mito estudantil no campo das resistências pós-golpe de 1964, a partir da obra que completa cinquenta anos em 2018.

Palavras-chave: Arthur Poerner. Movimento Estudantil. Resistência Cultural

\section{ECHOES OF MEMORY AND STUDENT RESISTANCE: THE YOUNG POWER (1968) BY ARTHUR POERNER FIFTY YEARS LATER}

ABSTRACT: The book The Youth Power (O Poder Jovem) and its author Arthur Poerner were at the center of debates about cultural and political resistance to the civil-military dictatorship established in 1964. Both the author and the book can be interpreted from the political events initiated with the signature of Institutional Act No. 2 from 1965 to 1968 and the publication of Institutional Act No. 5. Arthur Poerner had his political rights revoked because of AI-2 and the book The Youth Power was launched in 1968 and immediately censored. This book, from its launch until its re-editions in the following decades, had an important influence in the student's movement, being, inclusively, a mean of reconstructing the memory of this movement and the UNE. This article analyses how Poerner fomented the creation of a student

\footnotetext{
1 Doutorando pelo Programa de Pós-graduação em Sociologia do IFCH-UNICAMP. Endereço eletrônico: thiagobc.castro@gmail.com.
} 
myth in the field of post-coup resistances in 1964, starting with the work that completes fifty years in 2018.

Keywords: Arthur Poerner. Student Movement. Cultural Resistance.

\section{ECOS DE LAMEMORIA Y RESISTENCIA ESTUDANTIL: EL PODER JOVEN (1968) POR ARTHUR POERNER CINCUENTA AÑOS DESPUÉS}

RESUMEN: El libro El Poder Joven y su autor Arthur Poerner estuvieron en el centro de los debates sobre la resistencia cultural y política a la dictadura civil-militar instaurada en 1964. Tanto el autor como la obra pueden ser interpretados a partir de los actos políticos iniciados con la firma del acto $\mathrm{Y}$ en el caso de que se produzca un cambio en la calidad de la información. Este libro, desde el lanzamiento hasta sus reediciones en las décadas siguientes, tuvo una importante influencia en el movimiento estudiantil, siendo, incluso, un medio de reconstrucción de la memoria de este movimiento y de la UNE. Este artículo analiza la forma en que Poerner fomentó la creación de un mito estudiantil en el campo de las resistencias post-golpe de 1964, a partir de la obra que completa cincuenta años en 2018.

Palavras Clave: Arthur Poerner. Movimiento Estudiantil. Resistencia Cultural.

\section{Introdução}

Muito já se escreveu sobre o emblemático ano de 1968, dos eventos políticos do Brasil e do exterior, as transformações sociais e econômicas pelas quais o país atravessava, aos avanços nos campos da ciência e tecnologia. Agora, nas efemérides de cinquenta anos desse tão aludido e famigerado 1968, uma série de temas ressurge nos debates acadêmicos e políticos com a mesma relevância e significado que tivera meio século atrás. São como ecos que ressoam com maior intensidade e impulsionados pelo atual cenário de golpe de Estado, crises política e institucional, avanço das vozes conservadoras e reacionárias. Em contrapartida, se a imagem de hoje é a de "terra arrasada", estes mesmos ecos se expandem para os espaços de debates e pesquisas, como as escolas e universidades, e demonstram que, assim como em 1968, ainda existem núcleos de resistência política e cultural.

Não é de hoje que a relação entre estudantes - secundaristas e universitários -, política e cultura é mediada por linhas tênues, que facilmente se rompem em momentos de tensão política, expressões de autoritarismo, censura e afins. Este artigo aborda justamente essa relação que foi descrita pelo jornalista Arthur Poerner em seu livro O Poder Jovem, lançado pela editora Civilização Brasileira (ECB) em 1968. Uma história escrita há cinquenta anos, mas que recupera os primórdios dos movimentos estudantis no Brasil.

Os debates em torno dos contornos políticos do movimento estudantil na década de 1968 foram importantes na reconfiguração das lutas e das resistências à ditadura militar. Não 
apenas entre os estudantes o tema floresceu com força, mas também entre parcela significativa de uma intelectualidade de esquerda que tomou a expressão do movimento como uma forma renovada de exercício de debates sobre os rumos da democracia sob um governo militar.

Foi nesse contexto de transformações estruturais da sociedade brasileira que o jovem carioca Arthur José Poerner, ainda com seus vinte e poucos anos, estabeleceu-se na cena intelectual carioca como editor do Folha da Semana, periódico que circulou entre 1965 e $1966^{2}$. Semanário caracteristicamente alternativo em formato tabloide que Poerner editou com a colaboração de um núcleo de intelectuais de várias matizes ideológicas. Dentre os nomes que colaboraram com a publicação estavam uma parte significativa da esquerda e dos liberais do Rio de Janeiro, como Sérgio Cabral, Maurício Azedo (secretário), Otto Maria Carpeaux, Leandro Konder, Carlos Nelson Coutinho, Paulo Francis, Marcio Moreira Alves e Luís Carlos Maciel. A Folha da Semana, segundo Bernardo Kucinski, "foi o único alternativo não efêmero dessa fase, completando quinze meses de vida. Até que em julho de 1966, deu-se a cassação dos direitos políticos de Poerner" (KUCINSKI, 2001, p. 30). Em virtude disso, Anderson Campos assumiria a direção do jornal até dezembro do mesmo ano, quando novamente o jornal, enquadrado no Ato Institucional $n^{\circ} 2$ (AI-2), foi proibido e fechado por decreto presidencial e sua redação ocupada por fuzileiros navais.

Com o encerramento das atividades da Folha da Semana, Poerner pôde se dedicar à elaboração daquela que é a obra que o tornou uma das figuras mais importantes no cerne do movimento estudantil a partir de 1968. O livro $O$ poder jovem teve grande repercussão naquele ano dada a intensa agitação e politização do movimento de estudantes face ao recrudescimento da ditadura militar e da repressão às oposições. O crítico literário Otto Maria Carpeaux, ao escrever uma resenha sobre livro, publicada na Revista Civilização Brasileira, edição 19/20 de 1968, relaciona a obra a partir das ondas de manifestações estudantis que ocorriam naquele momento em várias partes do globo. Segundo Carpeaux,

a participação política dos estudantes brasileiros enche, todos os dias, as colunas dos jornais. Mas quem pretende informar-se sobre as origens e a evolução desse movimento não encontra, ou antes: até ontem não encontrou nada. Não existe, por mais estranho que pareça, nenhum livro sobre a história e sobre o sentido histórico

\footnotetext{
${ }^{2}$ Sobre o jornal Folha da Semana, consultar: CASTRO, Thiago Bicudo. Arthur Poerner entre intelectuais $e$ estudantes: representações intelectuais no jornal Folha da Semana e no livro O Poder Jovem. Dissertação Mestrado em Ciências Sociais). Faculdade de Filosofia e Ciências, Universidade Estadual Paulista "Julio de Mesquita Filho". Marília, 2016. Orientador: Prof. Dr. Rodrigo Czajka.
} 
do movimento estudantil brasileiro. Teve Arthur José Poerner a ideia de escrever um livro sobre o assunto. É uma obra que merece ser chamada de original. E essa obra sai num momento preciso em que o movimento estudantil explode e adquire força inesperada no Brasil e no Japão, na Argentina e no México, no Uruguai e nos Estados Unidos, na França e na Espanha, na Polônia e na Itália, na Alemanha e na Holanda e assim em diante. A atualidade do assunto - e do livro - é um fato (CARPEAUX, 1968, p. 303).

Considerado a "bíblia" do movimento estudantil, inclusive em pronunciamentos atuais da direção da União Nacional dos Estudantes (UNE), em eventos das efemérides dos cinquenta anos do golpe militar de 1964, a obra de Poerner enaltece a história do movimento e reafirma os sujeitos-heróis, demonstrando que os estudantes são "possuidores de um projeto nacional e progressista que, ao longo da história do país, sempre se fez presente" (POERNER, 1979, p. 207). A obra, de fato, conseguiu preencher uma lacuna na bibliografia sobre o movimento estudantil ou da história dos estudantes no Brasil ${ }^{3}$. Conforme Antônio Houaiss, que redigiu um texto de apresentação na ocasião da segunda edição, em 1979, o trabalho "constitui uma tentativa de balanço do movimento estudantil brasileiro, da colônia aos nossos terríveis dias." Assim, é verdade afirmar que $O$ poder jovem se situou num momento de incipiência política dos movimentos estudantis no contexto mundial, e que um dos objetivos centrais do empreendimento de Poerner era possibilitar o debate para a tomada de consciência do movimento estudantil brasileiro em consonância com as experiências realizadas em outros países. As sublevações revolucionárias levadas a cabo de diversas maneiras e em inúmeros países no ano de 1968 foram desencadeadas por movimentos políticos e sociais de jovens, muitos deles vinculados a seus respectivos movimentos estudantis nacionais.

Em seu texto, Poerner optou por conduzir a narrativa temporal de forma linear com apoio de documentos e inúmeros depoimentos de ex-integrantes da União Nacional dos Estudantes (UNE). O livro foi dividido em duas extensas partes intituladas "Antes da UNE" e “a partir da UNE", respectivamente. No que diz respeito aos eventos descritos e analisados pelo autor, sobretudo ao longo da segunda parte, tornam-se objeto instigante de análise, pois revelam, direta ou indiretamente, a forma pela qual se deu a pesquisa de Poerner sobre os desdobramentos políticos e ideológicos que impactaram a UNE. Noutras palavras: a segunda parte da obra descreve a conjuntura na qual o jovem jornalista, ele próprio, se situou, demonstrando também - ainda que involuntariamente - as relações e a proximidade que manteve com os estudantes na vigência da primeira fase da ditadura militar, uma vez que o próprio Poerner circulava nos meios estudantis. Tal proximidade revela-se, 11 anos depois, no

\footnotetext{
${ }^{3}$ A produção de autores contemporâneos a Poerner e, que abordam o tema da história do movimento estudantil, independente da perspectiva, é escassa. O que se vê é basicamente ensaios com análises de conjuntura e artigos em revistas.
} 
reconhecimento e no esforço desempenhado pelos estudantes em se organizar para a reedição clandestina de $O$ poder jovem no ano de 1977 . Portanto, torna-se significativo compreender a forma pela qual as memórias do movimento estudantil deslindadas por Poerner fizeram constituir um instrumento de luta e resistência dos estudantes em diferentes fases da composição e recomposição do movimento estudantil no Brasil. E, da mesma forma, colocar em realce a maneira pela qual a própria UNE aderiu à narrativa elaborada por Poerner, tornando-o um dos principais intelectuais porta-vozes do movimento estudantil nacional.

\section{2. $O$ ressurgimento de $O$ poder jovem}

Embora a obra originalmente date de 1968, neste ano foi impedida de ser editada com proibição de sua publicação e venda. Ainda que a censura a obras bibliográficas existisse, ela se dava de forma assistemática. Então, a necessidade de relançar o livro $O$ poder jovem no ano de 1977 permite-nos observar que, ao contrário do cinema, do teatro e da imprensa, por exemplo, o setor livreiro não fora atingido pela censura com a mesma intensidade ou pelo mesmo não com o mesmo rigor das demais áreas da produção cultural. De acordo com Ana Maria Machado "a censura, que atingiu tão duramente o teatro, a música popular e a imprensa nos anos 70, até que comparativamente poupou a literatura de danos maiores, deixando maior margem de atuação para denúncia e obras engajadas - salvo fatos ocasionais como a apresentação de Feliz Ano Novo [de Rubem Fonseca] ou a proibição de Zero [de Ignácio de Loyola Brandão]" (1994, p. 80).

Neste ano, a literatura ganhou destaque e, apesar da censura, 1977 foi chamado de “Ano político" pela revista Veja, em sua edição de 04 de janeiro de 1978. Durante toda aquela década livros categorizados de esquerda ou apenas de oposição ocuparam o topo das listas entre as publicações de maior sucesso. A VII Bienal Internacional do Livro de São Paulo, em 1980, trouxe uma série de publicações contendo relatos e memórias de parlamentares de oposição e intelectuais brasileiros, ao lado de Che Guevara, Trotsky, Mao Tsé-Tung, Ho Chi Minh e outros (MAUÉS, 2013, p. 10-11).

O ano de 1977, mais especificamente, conforme estudo de Hallewell (2012, p. 659), “assistiu a uma enxurrada de títulos políticos, especialmente de membros do MDB”, embora ele mesmo assinale que a "abertura" aos livros, iniciou-se efetivamente após a posse de João Figueiredo, em março de 1979 (HALLEWELL, 2012, p. 659; MAUÉS, 2013, p. 11).

O livro de Arthur Poerner, proibido em 1968, havia sido editado por Ênio Silveira, proprietário da editora Civilização Brasileira, que estava sob a ameaça da repressão e havia 
sofrido um atentado a bomba no mesmo ano. O próprio Poerner, dois anos antes, havia tido seus direitos políticos suspensos por dez anos. Contudo, demais livros de autores clássicos do pensamento de esquerda passavam sem vetos e Sandra Reimão (2011, p. 24) demonstra que nos primeiros anos da ditadura militar não houve estruturação de um "sistema único de censura a livros", eis que durante 1964 até 1969, diversos livros de autores de esquerda e clássicos internacionais da literatura erótica constaram nas prateleiras das livrarias ${ }^{4}$.

Apenas em 1970 a censura prévia para livros foi regulamentada pelo decreto-lei 1077/70. Os artigos previam um maior controle sobre livros que atentassem à moral e aos bons costumes, conforme se via no artigo $1^{\text {o: }}$ "Não serão toleradas as publicações e exteriorizações contrárias à moral e aos bons costumes quaisquer que sejam os meios de comunicação". Na sequência, o artigo $2^{\circ}$ determinava que "caberá ao Ministério da Justiça, através do Departamento de Polícia Federal verificar [...], antes da divulgação de livros e periódicos, a existência de matéria infringente da proibição enunciada no artigo anterior".

No que tangia às sanções, o artigo $3^{\circ}$ dispunha que: "Verificada a existência de matéria ofensiva [...], o Ministério da Justiça proibirá a divulgação da publicação e determinará a busca e a apreensão de todos os seus exemplares", e sobre divulgação e venda no artigo $5^{\circ}$ : “A distribuição, venda ou exploração de livros e periódicos que não hajam (sic) sido liberados ou que tenham sido proibidos, após a verificação prevista neste Decreto-lei, sujeita os infratores, independentemente da responsabilidade criminal".

Dessa forma, ainda que se fizesse presente a censura, esta se limitava aos temas da chamada moralidade e dos bons costumes. Entretanto, as "leis de exceção a que o País estava submetido [...] alargaram sobremaneira o entendimento do que poderia ser considerado, para poder ditatorial, adequado em relação a esses temas" (MAUÉS, 2013, p. 52).

Apesar das interferências diretas da repressão, a década de 1970 foi marcada por um movimento de revitalização das editoras com perfil oposicionista e político. Consagradas ou não, vinculadas a organizações e partidos políticos ou não, uma parte considerável editava obras com perspectiva crítica ao regime e mesmo à militância no pós-64 (MAUÉS, 2013, p. $13)$.

Neste cenário é que, em 1977, o movimento estudantil relança clandestinamente a segunda edição de $O$ poder jovem, numa forma de contribuição que denominada de edição política com base na terminologia de Flamarion Maués (2013, p. 25):

\footnotetext{
${ }^{4}$ Sandra Reimão (2011, p. 21) comenta que, apesar de não haver uma censura regular nos anos do governo de Castelo Branco, pouco se fez para impedir ações terroristas de grupos de extrema-direita que depredavam livrarias e editoras que publicassem e vendessem obras de autores comunistas.
} 
A edição política pode ser definida como aquela que vincula de modo direto engajamento político e ação editorial, o que significa dizer que é a edição feita com intenção política de intervenção social, ou seja, que parte de um projeto editorial e/ou empresarial de fundo político, cujo objetivo é promover a divulgação e o debate de determinadas ideias políticas publicamente na sociedade, posicionando-se em defesa dessas ideias.

Dadas as maneiras pelas quais os estudantes se articularam durante todo o período da ditadura militar, e que foram evidenciadas na obra de Poerner, observa-se que sua reflexão, assim como a construção da identidade política do estudante brasileiro foram incorporadas pelo movimento estudantil como se fossem seus próprios símbolos. Estes foram apropriados e recriados em diferentes momentos do movimento estudantil, sobretudo nas fases em que necessitaram de elementos para recompor institucionalmente a UNE, retomar a sua história e revitalizar a memória de combatividade dos estudantes na cena política e social. Assim, o livro $O$ poder jovem se tornou tanto uma fonte de recomposição da memória, mas também como referência bibliográfica e histórica às análises do e sobre o movimento estudantil. E será justamente neste segundo ponto em que se aprofundará a discussão, sobre como a instrumentalização da obra de Poerner constitui-se como referência principal nos estudos sobre movimento estudantil e juventude, bem como ela fornece algumas representações mitificadas e/ou tipificadas do estudante como ator político central nos movimentos sociais nas décadas de 1960 e 1970.

\section{Tipos e Mitos da memória estudantil}

De acordo com Ianni (2002, p. 185) os caminhos de uma reflexão que visa uma ““compreensão' ou [...] 'explicação', pode levar consigo algo, ou muito, de fícção. A realidade transfigura-se em conceito e categoria ou metáfora e alegoria. Estas metáforas são frequentes, às vezes, inevitáveis". As representações são desdobramentos discursivos das metáforas que determinados atores sociais - neste caso, intelectuais - estabelecem a partir da consideração que fazem sobre seus objetos de análise. Mais ainda: as inserem em determinadas linhagens de pensamento ou "família" de explicações do Brasil. São, nas palavras de Octávio Ianni "várias inquietações, interrogações ou mesmo interpretações que se elaboram nesses e em outros estudos e narrativas, destinados a esclarecer a história, descrever as épocas, explicar as raízes ou descobrir as perspectivas do país, sociedade nacional, povo ou Estado-Nação”. (2002, p. 179). 
Ainda de acordo com Ianni (2002), no imaginário desses intérpretes, a partir do qual emergiram essas "linhas de pensamento", há pelo menos cinco grandes narrativas que visam compreender e explicar o Brasil. Resumidamente elas compreendem: 1) Estado como constituidor da sociedade civil, sendo esta pouco organizada e dispersa. Dessa forma, o Estado promove as mudanças e as direções de seu desenvolvimento, ou seja, tutela a estruturação sociedade em conformidade com o interesse das elites; 2) o Brasil como amplamente determinado pelos movimentos dos mercados externos, do colonialismo ao globalismo; 3) país marcado pelo patriarcalismo que se desenvolve no curso dos séculos de práticas escravistas, resultando em diversos desdobramentos. Dentre eles, uma contínua associação, mescla ou confusão entre as dimensões do público e do privado; 4) a singularidade de ser uma "democracia racial", a despeito dos séculos de escravismo e na forma como são tratados prática e ideologicamente o índio, o negro, o estrangeiro etc, um verdadeiro "laboratório racial"; e 5) um "lusotropicalismo" que fez o Brasil se destacar através de uma "história incruenta", de "revoluções brancas", na qual desenvolve-se a "democracia racial" (p. 179).

Inúmeros intelectuais e teóricos sociais dos séculos XIX e XX tornaram-se partidários de uma ou mais das tipologias sugeridas por Ianni. São alguns poucos exemplos: Silvio Romero, História da Literatura Brasileira; Joaquim Nabuco, O Abolicionismo; Euclides da Cunha, Os Sertões; Lima Barreto, O Triste Fim de Policarpo Quaresma; Mário de Andrade, Macunaíma; Caio Prado Jr., Evolução Política do Brasil; Sérgio Buarque de Holanda, Raízes do Brasil; Florestan Fernandes, A Revolução Burguesa, e outros tantos citados pelo sociólogo paulista.

Entretanto, o ponto central da análise empreendida por Ianni no documento em questão é o afloramento, a partir das interpretações fornecidas, de outra linha interpretativa. “Trata-se da visão do Brasil, de sua história, como uma constelação de tipos, com alguns dos quais se constroem tipologias, sendo que, em alguns casos, desdobram-se em mitos e mitologias" (IANNI, 2002, p. 180).

Essa dimensão, em princípio, não está desvinculada de alguma grande família de interpretação apontada por ele, pelo contrário, surge em consonância com elas, porém não se enquadra nos horizontes teóricos de correntes mais conhecidas nas Ciências Sociais, como no marxismo, por exemplo. Ianni detalha esse processo afirmando que: 
sociedade, a política e a cultura, seja em termos de estudos de ciências sociais, seja em termos de narrativas literárias, como setores ou círculos que podem ser tratados separadamente, nos quais haveria dinâmicas próprias, certa autonomia. É como se a história do país se desenvolvesse em termos de signos, símbolos e emblemas, figuras e figurações, valores e ideais, um tanto ou muito alheios às relações, processos e estruturas de dominação e apropriação com os quais se poderiam revelar mais abertamente os nexos e os movimentos da sociedade, em suas distintas configurações e em seus desenvolvimentos históricos (IANNI, 2002, p. 180).

Os "tipos" povoam o pensamento brasileiro por meio da literatura, das artes plásticas e se reproduzem no interior dos estudos das Ciências Sociais, por vezes "conferindo a alguns tipos e mitos outras e novas modulações" (2002, p. 181). A fim de decifrar as novas modulações, faz-se necessário traçar uma "cartografia" dos tipos e mitos no decorrer da nossa história e observar o clima intelectual, no qual um determinado tipo ou mito reaparece ou é inventado. Para Ianni, "são frequentes e às vezes, notáveis os tipos que se criam e recriam, taquigrafando a difícil e complexa realidade." (2002, p. 182).

Tomando por base as definições expostas por Ianni acerca dos tipos e mitos, torna-se plausível a hipótese, na qual Arthur Poerner, ao redigir e publicar O poder jovem no "calor" dos acontecimentos pós-golpe de 1964, tenha recorrido a uma análise sobre a história do movimento estudantil marcada por sua identificação/aproximação com os próprios estudantes, bem como com as diretrizes político-ideológicas que orientaram o movimento, criando um "tipo" explicativo para descrever os estudantes brasileiros e o seu processo de luta contra a repressão militar. A representação de um “despertar espontâneo" presente na tipificação que Poerner elabora em seu texto constata-se quando descreve, por exemplo, a atuação voluntarista dos estudantes na resistência que estes protagonizaram logo após o golpe que depôs João Goulart da Presidência da República. Em torno dessa questão, Flávia Santana (2007, p. 61) reforça essa ideia esclarecendo que, de fato, o movimento estudantil representou uma força não desprezível: "após o golpe, o movimento estudantil passou a ser considerado pelo regime uma das maiores forças oposicionistas, pela sua capacidade de mobilização popular e suas manifestações reivindicatórias anteriores". Por outro lado, há que se considerar que não se tratou apenas de uma politização automática espontânea do movimento estudantil, haja visto o crescimento do número de matrículas no ensino superior entre os anos 1960 e 1980 , oferecendo, portanto, uma base numérica significativa para o movimento ${ }^{5}$, aspecto

\footnotetext{
${ }^{5}$ Em estudo apresentado em 2003, o Núcleo de Pesquisas sobre o Ensino Superior, mostrou que: "O ensino superior universitário e não universitário se ampliou de maneira extraordinária, desde o início do regime, em 1965 até o final da década de 70. Em cerca de quinze anos, o número de matrículas no ensino superior passou de 95.691 (1960) para 1.345.000 (1980), sendo os anos de 1968, 1970 e 1971 os que apresentaram as maiores taxas de crescimento" (2003, p.17). Ao analisar especificamente o ensino público a pesquisa constata: matrícula no setor público aumentou, nesse período, de 182.700 a 492.000 , ou seja, teve um incremento de cerca de $260,0 \%$.
} 
elementar não apontado por Poerner. A proposição de Santana oferece o diagnóstico mais pontual da conturbada relação entre estudantes e o governo instaurado em 1964, orientando na forma de um ponto de partida para uma análise mais concreta. Assim como Mavi Rodrigues (2006) considera que:

\begin{abstract}
A inclinação dos estudantes dos anos 60 para o radicalismo de esquerda não se deve, segundo Hobsbawm (1998), a uma propensão natural da juventude para a rebeldia ou as paixões revolucionárias, ainda que isto possa ser levado em conta. A radicalização dos estudantes, no último quartel do século $\mathrm{XX}$, fora, além do choque entre um ingresso massivo de jovens no ensino superior e a limitada capacidade organizacional e intelectual das universidades para absorvê-los, igualmente fruto de um 'abismo de gerações' entre filhos do Pós-Segunda Guerra e seus pais (HOBSBAWM apud RODRIGUES, p. 60-61).
\end{abstract}

Ora, se houve em uma parcela do movimento estudantil e até mesmo em outros setores sociais a expectativa de que o Partido Comunista Brasileiro (PCB) se posicionasse prontamente contra golpe de $1^{\circ}$ de abril, ela certamente caiu por terra juntamente com o projeto histórico de aliancismo do partidão. E, de uma certa forma, isto nos assegura que a afirmação taxativa de Daniel Aarão Reis (1998, p. 30) sobre a resistência estudantil pós-golpe carece de ponderação, pois escreve este autor: "a rigor, a resistência dos universitários à instauração da ditadura fora débil. Poucos núcleos a ela se opuseram de forma decidida. Sem armas, foram rapidamente dispersados". Seguramente, o PCB já vinha de desgastes mesmo antes do golpe, inclusive perdendo espaço entre os estudantes e com dissidências formadas a partir de 1962 - muito em virtude do discurso aliancista e moderado.

A nova Constituição, imposta em 1967, firmou ainda mais a presença dos militares no governo. Portanto, o processo de estruturação do regime chegava até fins de 1968, com o recrudescimento da ditadura por meio da promulgação do AI-5. Não apenas os estudantes, mas tampouco o PCB chegava a construir consensos sobre os rumos a seguir entre seus próprios membros e as divergências não se limitavam à cúpula do Partido. Para Daniel Aarão: "As bases estudantis, envolvidas nos primeiros movimentos sociais, ganhavam autonomia. Fugiam ao controle das instâncias formais, estabeleciam relações entre si, inclusive no plano interestadual, mantinham contatos e recebiam influências da POLOP e do PC do B”. (REIS FILHO, 1990, p. 48).

(DURHAM, 2003, p.18). Marcelo Ridenti, por sua vez, exibe os seguintes dados, com base no artigo de Luiz Cunha intitulado A Expansão do Ensino Superior: causas e consequências. In: Debate e Crítica, n.5, 1975, p.34. "O número de vagas oferecidas ao ano no ensino superior brasileiro saltou de 35.900 em 1960 [...] para 89.592 em 1968. Mesmo assim, não dava conta da procura, exacerbando o problema dos 'excedentes', que obtinham média para serem aprovados, mas não entravam na universidade, devido à escassez de vagas. De 1966 a 1968 , o número de excedentes passou de 64.627 para 125.414." (2007, p.190). 
Na prática isso representou o rompimento com as tradições partidárias de "luta interna dos comunistas" (REIS FILHO, 1990, p. 48), cujos membros sempre dependiam de ordens da cúpula. As bases estudantis, portanto, "formavam um veio próprio desde 1965: a dissidência" 6 (REIS FILHO, 1990, p. 49). Em suma, “o PCB [...] atropelado pelos acontecimentos de março de 1964 e preocupado em garantir a integridade mínima dos seus quadros mais importantes, só conseguiu ter uma posição oficial diante do golpe em 1965, com a 'resolução de maio' do Comitê Central" (NAPOLITANO, 2011, p. 29).

A maneira como Poerner destacou a figura do jovem, juntamente com a sugestão da existência daquilo que ele denomina de "poder jovem", vem ao encontro das concepções que interpretam a juventude a partir de representações de caráter sociocultural para definir, unilateralmente, sua interação com as instituições. Disso se depreende que o trabalho de Poerner se situou na constatação de que a juventude possui uma força social renovadora, pois lhe foi atribuído algum tipo de poder. Como mencionado anteriormente, o modo como se construiu a tomada de consciência dos estudantes do Brasil em consonância com os de outros países, tal como descreve Poerner, supõe de antemão a inata capacidade de organização das massas estudantis no exercício da consciência democrática. Noutras palavras, O poder jovem serviu-se de uma narrativa laudatória e endossou uma memória construída sobre a resistência estudantil repleta de saudosismo, e que se desdobrou em simplificações sobre as reais atividades desenvolvidas pelo movimento estudantil. Segundo Poerner:

\begin{abstract}
A história da UNE e do movimento estudantil brasileiro se confunde, inteiramente, a partir de abril de 1964, com a história da repressão às liberdades e da intervenção estrangeira no Brasil. De um lado a Lei Suplicy de Lacerda. De outro, o Acordo MEC-USAID. Os estudantes, que vinham de conquistas como a duplicação de vagas na Universidade do Brasil (atual Universidade Federal do Rio de Janeiro) - para isso, o Presidente Goulart liberara, em 10 de março de 1964, uma verba de dois bilhões de cruzeiros (velhos) -, passaram, automaticamente, à condição de elementos de alta periculosidade para a segurança nacional, aos olhares 'eternamente vigilantes' das novas autoridades. Ser estudante equivalia a ser 'subversivo' (POERNER, 1979, p. 218).
\end{abstract}

Com esta passagem, Poerner informa-nos que os estudantes sofreram intervenções severas em suas organizações, o que consequentemente teria levado sua entidade máxima à clandestinidade. Mais do que isso, no entendimento de Poerner - que não custa frisar, analisou os eventos não por uma ótica crítica ou com um distanciamento de seu objeto, já que sequer era essa sua intenção, mas realçar sua memória e vivência no meio estudantil —, há uma tentativa sistemática de desarticulação dos estudantes universitários no interior de seu

\footnotetext{
${ }^{6}$ Daniel Aarão Reis Filho se refere à DG (Dissidência da Guanabara) que culminou na formação do MR-8.
} 
próprio espaço de representação intelectual e profissional: a universidade. Isso porque boa parte destes estudantes apresentados em $O$ poder jovem, dentre os quais emergiram muitos e importantes intelectuais nas décadas de 1960 e 1970, era o elo entre as classes populares e as classes médias e até elite, no Rio de Janeiro e em São Paulo. Também se constata que certa memória social tem descrito o interregno 1964-1968, como sendo de relativa liberdade de expressão, atribuindo a esse período a denominação de “ditabranda". Para Marcos Napolitano a explicação para isso é que o governo militar possuía, de imediato, duas questões a serem sanadas. A primeira era colocar sob suspeição os quadros do regime deposto, investigá-los e puni-los; e a segunda era causar rupturas nos elos existentes entre ativistas políticos culturais de esquerda e os movimentos sociais - movimento estudantil, por exemplo. Inclusive, quando a onda de protesto de avoluma no decorrer da década de 1960, principalmente entre a classe média, muitos jovens oriundos do movimento estudantil que se rearticulou em 1966, passam a realizar vastas passeatas nas ruas (2011, p. 39, 45).

O regime buscou conter o suposto avanço da ideologia comunista entre os universitários e assegurar o controle administrativo das universidades públicas. Como desdobramento dessa situação, ainda no governo do Castelo Branco (1964-1967), foi promulgada a Lei Suplicy de Lacerda ${ }^{7}$, tendo importante repercussão entre os estudantes. "No primeiro ano de mandato de Castelo, circulavam pelo país notícias que informavam sobre o envio de uma mensagem do ministro da Educação, Suplicy de Lacerda, ao Congresso sugerindo a extinção da UNE" (SANTANA, 2007, p. 62) ${ }^{8}$. Para Arthur Poerner, o ponto positivo da iniciativa do ministro Lacerda foi que ela provocou a rearticulação dos estudantes após o golpe e que a lei em questão teria sido o elemento motivador para que isso ocorresse. Conforme demonstrou Poerner, a "Lei Suplicy de Lacerda apresentou, contudo um grande mérito: o de aglutinar, na luta pela sua revogação, o movimento estudantil, que atravessava, naturalmente, uma fase de reorganização, como consequência da perseguição aos seus líderes" (POERNER, 1979, p. 231).

\footnotetext{
7 “'Suplicy, o mais catastrófico ministro da Educação na história da pedagogia nacional, fora até o início de 1964 um modesto reitor da Universidade Federal do Paraná. Viu-se catapultado ao gabinete pelo general Ernesto Geisel, que conhecera anos antes, quando servia em Curitiba. Chamava de 'escorpiões' e agitadores e pequenos ladrões transformados em líderes os estudantes que faziam passeatas contra o governo" (GASPARI, 2002, p.225). Mais à frente encontra-se um aprofundamento sobre esse tópico.

${ }^{8}$ Em 1964 a UNE foi extinta (lei no 4464). Dessa forma, a entidade deveria ser substituída pelo Diretório Nacional dos Estudantes e as Uniões Estaduais pelos Diretórios Estaduais (DEES), extinguindo as entidades estudantis autônomas por outras vinculadas ao regime. A Lei Suplicy de Lacerda concedia a ao Ministério da Educação a convocação dos Diretórios Nacionais e Estaduais, ferindo o princípio da autonomia estudantil (cf. GASPARI; POERNER, ibidem, ibidem, p.226, 231).
} 
João Roberto Martins Filho atesta a reorganização do movimento estudantil no imediato pós-golpe de $1^{\mathrm{o}}$ de abril. Segundo ele, "é possível dizer, assim, que, logo nos primeiros meses, o regime deparou-se com uma oposição difusa e não-articulada no meio estudantil, que se aprofundaria depois com a luta contra a 'Lei Suplicy'” (1986, p. 97). Martins Filho detalha as dificuldades que a UNE enfrentava para se articular enquanto unidade de representação dos estudantes, a razão para isso viria das disputas entre a esquerda e os liberais pelo controle da entidade. Com isso, "as primeiras manifestações de descontentamento do meio universitário diante das medidas anunciadas pelo governo militar originaram-se das entidades que haviam escapado ao fechamento e à repressão, porque haviam se colocado tacitamente a favor da intervenção militar". (MARTINS FILHO, 1986, p. 108).

Martins Filho, portanto, consegue reforçar este aspecto, que não é esclarecido no livro de Poerner: o de que uma parcela de estudantes liberais apoiaram o golpe. Para Saldanha de Oliveira (2005, p. 51), Arthur Poerner ignorou essa questão, porque "esse comportamento não condiz com a "tradição estudantil."'. Outro ponto acrescentado por Martins Filho se refere aos dados estatísticos que serviram como uma das bases de sustentação do argumento de Poerner. Martins Filho questiona, ao afirmar que:

\begin{abstract}
para fins de análise, interessa sobretudo destacar que o repúdio à política autoritária para a universidade se constitui num ponto comum ao conjunto da categoria estudantil, logo depois do golpe. Desse modo, embora não atingisse as proporções que a historiografia do movimento tem lhe atribuído, o plebiscito realizado pela UNE em março de 1965 expressaria uma significativa condenação da 'Lei Suplicy' no seio do estudantado. Por outro lado, a luta contra a legislação autoritária se configuraria na motivação inicial para a reaglutinação política e organizativa do movimento, durante o ano de 1965 e, nesse quadro, criam-se as condições iniciais para a gradativa retomada de influência da esquerda (MARTINS FILHO, 1986, p. 116, grifo nosso).
\end{abstract}

E o mesmo autor, em nota de rodapé, termina seu raciocínio confirmando:

Num total de 24.513 estudantes universitários da Guanabara, foram consultados 7.584 e os votos contrários à lei atingiram $80 \%$. Estes dados estão em BRITO, Sulamita. 'A juventude universitária e a política' em Cadernos Brasileiros, Rio, julho-agosto de 1968, no 48, pp. 5-19. Aí, Sulamita afirma que a dificuldade de conseguir dados [...] poderia ser atribuída 'ao receio dos estudantes em fornecer dados exatos da amplitude ou debilidade do movimento estudantil'. Há notícias sobre os resultados de São Paulo em O Estado de S.Paulo, edições de 26 a 31 de março de 1965. O repúdio à lei coincidiria assim com o primeiro aniversário do golpe. Por outro lado, os dados divulgados pela UNE e citados por Poerner, segundo os quais $92,5 \%$ dos universitários de todo o país votaram contra a lei parecem bastante improváveis (MARTINS FILHO, 1986, p. 116, grifo do nosso). 
Neste caso, a forma pela qual Poerner conduz a premissa do "poder jovem" no interior da sua obra, atesta a necessidade que o autor tem de construir uma determinada imagem do movimento estudantil na década de 1960. O texto traz imprecisões conforme demonstra Martins Filho, mas isso não invalida a obra e aquilo que ela representa enquanto instrumento intelectual de uma resistência à ditadura de 1964. Imprecisões que revelam as escolhas que seu autor fez no momento da composição de uma identidade social e política do estudante e do movimento a que pertencia. E ainda: como o próprio Poerner ver-se-á representado no fluxo dos acontecimentos e dos fenômenos de resistência estudantil, não apenas como observador, mas sobretudo como um ator que fala dos e para os estudantes.

\section{Estudantes, jovens e rebeldia}

A questão que se coloca a partir destes posicionamentos de Poerner e da precedente análise é a mesma postulada por Claudia Gusson (2008, p. 53), quando a autora indaga: "a militância do movimento estudantil estaria relacionada à condição de ser jovem ou de ser estudante?". Por mais tautológico que pareça o questionamento de Gusson, seu sentido é pertinente, pois seria determinante à militância dos jovens serem estes todos estudantes? Uma vez que quem milita no movimento estudantil são os estudantes — assim sendo, nossa premissa é de que seria necessário ser estudante para militar no movimento estudantil —, há quem preferisse não participar. Portanto, a condição de ser jovem seria também determinante? De que modo isso poderia ser respondido à luz das hipóteses de Poerner, considerando seu entendimento sobre a militância estudantil no período após o surgimento da UNE, especialmente nos anos que se sucederam ao golpe de 1964 ?

A questão que se propõe aqui lança mão de duas ideias que defendem a primazia da condição de estudante para a militância estudantil — ou seja, independente da faixa etária —, relegando a um segundo plano a condição juvenil, caracterizada na noção de "poder jovem". "A primeira apresenta o estudante sempre na condição de disponibilidade de engajamento político para a defesa das causas sociais. A segunda encara a atuação reivindicatória do estudante como um trampolim social de suas aspirações de classe de origem”. (RESENDE apud GUSSON, 2008, p. 57).

A primeira tendência é bastante criticada por alguns historiadores e sociólogos que investigam ou investigaram a atuação do movimento estudantil brasileiro em diferentes contextos, uma vez que relaciona a participação política dos estudantes com a defesa das classes desfavorecidas. Gusson resgatou em João Roberto Martins Filho e Daniel A. Reis 
Filho as posições críticas frente a esta tendência. Segundo a autora, Martins Filho explica que a visão de um estudante como agente defensor das camadas menos favorecidas não passou de uma "mitologia" estudantil e que é preciso superar a ideia de que o estudante no Brasil sempre esteve ao lado do povo brasileiro em todas as suas lutas. Reis Filho, segundo Gusson, segue o mesmo raciocínio e lembra que a militância estudantil não está predestinada a ser questionadora, tampouco revolucionária. Por seu turno, Reis Filho (1998, p. 29) afirma que os estudantes universitários "são atravessados pelas questões que agitam a sociedade, e que não podem ser reduzidas à problemática da origem de classe". Este ainda complementa seu entendimento sobre os falsos atributos concedidos aos estudantes, afirmando que "os estudantes nem sempre desempenharam, e nem estão destinados a desempenhar [...] um papel questionador, ou reformista, e muito menos revolucionário, na história do país, ou de qualquer lugar do mundo" (MARTINS FILHO, 1986, p. 29). Logo, ambos os autores colocam a origem de classe como influência fundamental na atuação estudantil entre os jovens.

A segunda tendência considera os estudantes não como defensores das camadas pobres da sociedade, mas sim como representantes de uma atuação política que resulte na sua ascensão social, independente da classe social da qual originam. Gusson atenta às possíveis confusões que tal interpretação pode ocasionar. Isso posto, novamente nos conduz a Martins Filho, além de Marialice Foracchi, para os quais a ênfase da análise concentra-se na origem de classe, mas considerando que "existe o risco de entender o engajamento dos estudantes em manifestações políticas como atitudes oportunistas e individuais” (GUSSON, 2008, p. 58). No entanto, inseridos numa coletividade, os anseios particulares são superados no intuito de perfazerem um projeto maior. "A militância estudantil é uma luta de caráter coletivo, esboça uma ruptura da ordem vigente e não se trata mais da tentativa isolada de ascensão social, através da educação, de indivíduos menos ou mais pobres" (RIDENTI apud GUSSON, 2008, p. 59).

No que tange à redação de $O$ poder jovem, há algumas passagens que asseguram o posicionamento de Poerner na defesa dos estudantes como sujeitos combativos, portadores de ideais em defesa do povo, reforçando a tese de Martins Filho acerca da circulação de uma mitologia estudantil. Isso posto, é preciso considerar que a interpretação que Poerner ofereceu em sua obra deve ser problematizada no contexto de referência da origem de classe dos estudantes universitários, a "pequena burguesia ascendente" ou simplesmente "classe média"9

\footnotetext{
${ }^{9}$ Foracchi (1965, p.221) esclarece em nota a origem da expressão por ela utilizada: Lewis Corey. "The Middle Class", in. Bendix and Lippsett, Class, Status and Power, p.373; C. Wright Mills, The White Collar, The American Middle Classes; David Riesmann, The Lonely Crowd - A Study of the American Changing Charater.
} 
(FORACCHI, 1965, p. 221). Ridenti acena na mesma direção, já que considera relevante compreender a especificidade da situação de estudante, que se compõe como "transitória entre as classes de origem dos universitários e as classes que ajudarão a constituir depois de formados" (1993, p. 141). O movimento da sociedade de classes é o limiar das lutas estudantis, isso faz do movimento estudantil um indicador dos problemas da sociedade como um todo.

A “classe média" está, para Foracchi (1965), numa relação de dependência, com as demais classes, e isto sugere que sua ação seja ambivalente. Por um lado, ao ser assalariada, a classe em questão se vincula às camadas populares, compartilhando reivindicações, mas de modo tímido; por outro lado, também se vincula a estratos dominantes e de elite, em termos de dependência e subordinação, incapacitando-a para uma tomada de posição que exija ruptura. No bojo do movimento estudantil o projeto de muitos de seus integrantes se apresentava com vistas à carreira. Poerner não buscou ampliar a ideia de que o movimento estudantil se empenhou intensamente na luta dos setores médios pela abertura da universidade, o que ele manifesta no trecho a seguir corrobora com tal concepção e serve de parâmetro para uma análise mais abrangente:

\footnotetext{
É claro que o universitário poderia dizer: 'Bem, pelo menos o meu diploma está garantido [referindo-se aos dados oficiais apresentados a respeito do número de crianças e adolescentes que conseguem se formar no ensino básico e dos que ingressam nas universidades, além dos investimentos nestas instituições] Quanto menos formados haja, menor a concorrência. Em terra de cego, quem tem olho é rei'. A atitude da maioria deles, no entanto, tem sido diversa. Eles recusam o título de príncipes de uma sociedade subdesenvolvida, lutando para que todos tenham acesso ao ensino, e enfrentam, por conseguinte, a força poderosa dos que precisam de um Brasil atrasado (POERNER, 1979, p. 302 et seq).
}

Marcelo Ridenti procura ir além e vincula a luta dos estudantes ao caráter classista da sociedade brasileira. Segundo ele, considera que "o acesso à universidade seria parte do projeto de ascensão social dentro da ordem capitalista, projeto da classe média, ou pequeno-burguesa" (RIDENTI, 1993, p. 144). De forma não acintosa, o que as camadas médias estavam fazendo era estimular a ascensão social por meio do acesso à universidade, alimentando a ilusão de elevar-se socialmente, entre os setores menos favorecidos, fazendo assim oposição à ideologia proletária. Ridenti esclarece que a ilusão da ascensão social via estudos é compartilhada por todos os segmentos sociais despossuídos. Alimentar essa ilusão é requisito para a manutenção da ideologia burguesia na sociedade, uma vez que "a ordem social capitalista é a única que os despossuídos conhecem - nada mais legítimo que procurem 
ascender dentro dela" (1993, p. 144). A luta pela ascensão social com caráter coletivo assumido pelo movimento estudantil nos anos 1950/60, apesar de esboçar uma ruptura, ainda se mantém com objetivos visados dentro da ordem capitalista ${ }^{10}$. O que esta luta expressa, de fato, é uma busca conjunta por direitos de cidadania integrais, que fazia parte das aspirações dos despossuídos (RIDENTI, 1993, p. 144). Ora, a própria luta específica da classe média pela reforma e defesa do ensino não era alheia aos interesses imediatos dos trabalhadores. Grande parte disso que se chamou de "classe média ascendente" era formada pela classe trabalhadora, ainda que não sejam proletários propriamente ditos. Ridenti ressalta que "lutas populares por mudanças econômicas, políticas, educacionais e sociais em geral dentro da ordem capitalista, não são necessariamente revolucionárias, mas fazem parte do processo de constituição da classe trabalhadora" (1993, p.144). Na mesma linha argumentativa de Foracchi, ao reagir contra a influência conservadora sobre as universidades. "os estudantes estão tentando desatar os vínculos que prendem sua camada de origem a este tipo de ingerência conservantista e indicando, de certo modo, as potencialidades 'revolucionárias' da situação de classe em que se encontram" (FORACCHI, 1965, p. 224).

Desse prisma, compreendendo que Arthur Poerner não explorou a história do movimento estudantil à luz das teorias sociais e históricas, visando esclarecer os vínculos que não saltam aos olhos, presentes nas relações sociais que ele buscou nos expor, é que se identifica seus próprios aspectos de tipificação sobre os estudantes. Por não colocar em evidência a perspectiva de uma sociedade de classes, Poerner não traz ao leitor as aspirações de uma classe média que ascendia no Brasil paulatinamente nas décadas de 1950 e 1960. De acordo com Ridenti:

Assim, pode haver muito de mistificação ao se falar em aspiração de acesso ao ensino superior da parte das camadas médias. Tal aspiração é do conjunto dos trabalhadores na busca de direitos integrais do cidadão. (Naturalmente, a identificação de cada um como cidadão e sujeito de direitos tem um caráter ocultador da divisão da sociedade de classes) (1993, p. 145).

Outro aspecto de considerável relevância que pode ser identificado em $O$ poder jovem, e que se relaciona com o debate colocado anteriormente sobre as condições juvenil e estudantil, além das questões políticas e ideológicas que a obra apresenta, é a correspondência entre a própria juventude - tema central da obra - e os intelectuais, remetendo diretamente ao papel intelectual e político do autor livro.

${ }^{10}$ É possível dizer, portanto, que a ruptura é ideológica, mas não estrutural. Afinal, os estudantes coincidem discursos com os despossuídos, mas estruturalmente eles continuam no processo de ascensão socioeconômica, onde as classes desfavorecidas não têm lugar, a exceção dos discursos dos próprios estudantes. 
Poerner descreveu, por exemplo, a participação dos estudantes secundaristas em contraste com a dos universitários. Referiu-se aos secundaristas como sendo a "linha dura" do movimento estudantil, possuidores de tamanha disposição que chegava a assustar os universitários. Arthur Poerner elencou — a partir de sua própria experiência e convivência que estes secundaristas não tinham os medos que tinham os universitários:

\begin{abstract}
Além disso, eles não padeciam do medo de se 'queimar', que acometia muitos universitários quando, às vésperas da formatura, começam a se preocupar com a conquista de um lugar ao sol na sociedade que tanto combateram [...] demonstrava também, no mais alto grau, o caráter de generosidade e sadia inquietação da juventude brasileira (POERNER, 1979, p. 286).
\end{abstract}

Apesar de saudá-los, Poerner pouco explorou a participação dos secundaristas na luta estudantil dos anos de vigência do regime militar. Com isso, faz-se realmente difícil determinar o grau de envolvimento deste contingente e suas "armas" na luta contra os governos militares. Sem uma direção política estabelecida ou um arcabouço teórico que inspirasse as formas de resistir, estes estudantes poderiam receber a pecha de "rebeldes", com base em suas ações.

Uma possível compreensão desse aspecto da rebeldia e das atividades política empreendida pelos estudantes secundaristas é observar como se deu sua articulação a partir dos encontros estudantis no Calabouço - Restaurante Central dos Estudantes. Durante a década de 1960 este espaço foi paulatinamente ocupado pelos secundaristas, a medida em que restaurantes universitários eram instalados nas próprias faculdades. No Calabouço os estudantes secundaristas tinham direito, além de alimentação, a apresentações de música brasileira e acesso a boletins informativos. Havia ainda um curso supletivo ministrado por universitários, bem como uma clínica de assistência médico-dentária. Assim, o Calabouço representou uma alternativa aos estudantes mais pobres do Rio de Janeiro, a fim de permanecerem em seus estudos. Representou, além disso, a própria possibilidade de ascensão social a estes desfavorecidos, ou seja, uma forma de democratização de acesso ao ensino.

O golpe de 1964 encerrou as atividades do Calabouço por alguns meses, num ato político de desconstrução das medidas tidas como assistencialistas ou simplesmente "populistas", haja vista que o restaurante havia sido criado durante o segundo governo Vargas. A UNE e a União Metropolitana dos Estudantes (UMES) estavam na clandestinidade, dessa maneira, conforme analisou Rafael Hagemeyer, "ainda que os estudantes do Calabouço discutissem o aprofundamento do autoritarismo no país, e também dos movimentos de protesto, procuravam, apesar disto, manter sua autonomia em relação às outras entidades 
estudantis" (HAGEMEYER, 1997, p. 29). Outro dado a ser considerado como estopim, foi a proposta do governo de demolir o Calabouço para construir no lugar um trevo rodoviário, e posteriormente construir um novo restaurante em outro endereço. Então,

\begin{abstract}
"não se tratava de um novo restaurante mais moderno, e sim do significado afetivo do restaurante, onde os estudantes recebiam, além da comida, o alimento do espírito crítico de que ficariam privados em outro local, dada a larga autonomia que possuíam ali. [...] Para os estudantes do Calabouço fechava-se, assim, o elo da retórica da esquerda estudantil: a ditadura militar, vassala dos interesses do imperialismo americano representado pelo FMI, destruía a educação no Brasil, para alienar o povo, cortando seu acesso à universidade, este por sua vez simbolizado pelo Calabouço. Mais do que isso, declaravam que a construção do trevo universitário seria para 'facilitar o acesso da burguesia às suas praias'." (HAGEMEYER, 1997, p. 30).
\end{abstract}

Um terceiro estopim pode ser representado pelo assassinato do estudante Edson Luís, jovem de dezesseis anos que frequentava o restaurante e não costumava frequentar as passeatas e demais mobilizações, mas acabou assassinado pela polícia durante uma manifestação em defesa do restaurante. Na Folha da Semana encontramos outro caso que remete ao Calabouço. Um jovem maranhense que optou por tentar a vida no Rio de Janeiro, para poder completar os estudos e cursar Economia em alguma universidade pública, enquanto trabalhava. Segundo o jornal, que teve contato com os familiares e colegas de Zeca - apelido de Ezequiel Gomes da Silva - sua rotina consistia em trabalhar, estudar e fazer refeições no Calabouço. De acordo com as fontes, Zeca não tinha por hábito participar de manifestações contra o regime, porém com a decisão do Ministro da Educação de fechar o restaurante, uma passeata com mais de 300 estudantes ocorrera e Zeca estava entre eles. A polícia buscou reprimir a manifestação com uso de bombas e agressões físicas, até que, em certo momento, Zeca sofreu uma queda no meio da multidão que buscava proteção e, uma bomba estourara sob seu corpo, resultando es estilhaços pelo seu corpo e a amputação de um dedo da mão esquerda (MAIA, 1965, p. 16). Dessa forma, o aspecto da rebeldia e de que maneira ela se processou no interior do movimento estudantil, tendo como referência a organização do movimento estudantil não universitário, também amplia a discussão e remete a uma complexidade a qual Poerner não alcançara com $O$ poder jovem.

Leandro Konder, outro jovem intelectual na década de 1960 e ligado ao PCB, em artigo publicado na Revista Civilização Brasileira, em 1967, tratou do tema da rebeldia em sua relação com os jovens e de que maneira os intelectuais estariam envolvidos com este aspecto naquela década. No artigo intitulado A rebeldia, os intelectuais e a juventude, Konder alerta que "a rebeldia, por si só, não basta para que a conduta humana se torne libertária: é preciso que o inconformismo se exerça na direção certa" (KONDER, 1967, p. 136). O que 
chama atenção no artigo de Konder é o modo como ele procurou dar conta das dimensões políticas da rebeldia e da ação revolucionária. Leva em conta o fenômeno da inserção dos estudantes no debate político e o papel do intelectual em fornecer os instrumentais necessários para essa luta; isso, para que o jovem pudesse exercer a resistência consciente de sua ação e não simplesmente estagnar permanentemente no estágio da rebeldia que, segundo Konder, não possuía legitimidade política alguma (CZAJKA, 2015, p. 128).

É nesta intersecção que Poerner se situa, juntamente com seu livro. Seu trabalho foi, de certa forma, resgatar os elementos históricos, os fatos que escolheu para representar a luta do movimento estudantil e ordená-los cronologicamente. Outro dado que pode ser considerado como relevante para entender a projeção de $O$ poder jovem foi a maneira como a produção cultural na década de 1960 esteve estreitamente relacionada com a expansão de um mercado de bens culturais. Ou seja, a representação social de intelectuais como Poerner no terreno das produções culturais — através de suas publicações, fossem na forma de livros ou no seu ofício de jornalista - viu-se atrelada à estrutura de mercado de publicações editoriais. O crescimento do número de publicações durante a primeira metade da década de 1960 deveu-se, sobretudo, a esse aspecto sócio-político importante: o fortalecimento de espaços de debates - aqui expresso pela editora Civilização Brasileira, que publicou a primeira edição da obra - a fim de dar continuidade aos projetos outrora propostos no interior de instituições desmanteladas pelo golpe, como o ISEB e o CPC da UNE. Por outro lado, havia o aspecto sociocultural que permitiu fazer daqueles espaços o "lugar" da discussões e debates antes em curso (CZAJKA, 2010, p. 104). Portanto, o livro de Poerner caracterizou-se por fomentar um debate até aquele momento pouco explorado. Contudo, o valor de uma instituição estava garantido na sua existência concreta e na sua atuação efetiva na sociedade; um livro, uma revista ou um jornal representa esse valor no processo de recepção dos seus leitores, não à toa o livro recebeu censura já na sua publicação.

Nesse sentido, o artigo de Leandro Konder sobre a função social dos intelectuais esboçava uma preocupação que afligia não somente o autor, mas todo o conjunto da intelectualidade de esquerda que se via num processo complexo de organização das formações culturais de oposição e a sua inserção no espaço público ou no mercado. Konder, nesse caso, não se preocupava com essa inserção, mas com a maneira pela qual os intelectuais deveriam contribuir para a orientação (como agentes de uma vanguarda revolucionária) daqueles que, na segunda metade da década de 1960, promoviam mudanças significativas nas 
estruturas políticas e culturais da sociedade brasileira, a saber, os estudantes (CZAJKA, 2015, p. 113,128$)$.

Ainda que contemporâneo a essa discussão proposta por Konder, Poerner não se atenta ou ignora esse debate na redação de $O$ poder jovem. É inquestionável que o autor não se preocupou em realçar as ações de resistência dos estudantes, contribuindo, assim, para que estas ações, bem como seu livro fossem reificados, manipulados ainda hoje para a criação de um personagem com poderes intrínsecos, capazes de transformações dentro e fora das universidades. Portanto, $O$ poder jovem consagrou, intermediado pelas interpretações e utilizações que fizeram dele, um novo personagem "tipologizado" e mitificado do pensamento brasileiro, o jovem estudante.

Ainda hoje, o livro escrito por Arthur Poerner na década de 1960, encontra ressonância no movimento estudantil e na própria UNE, haja vista a utilização de uma memória de combatividade e o uso político do passado com a finalidade de dar coesão histórica à entidade. No intento de reconstruir a identidade da UNE entre 1978 e 1979, conforme aponta Angélica Müller (2010, p. 206), “o resgate da 'memória' da entidade, nesse momento, serviu de respaldo para a revalorização da UNE. Serviu também como uma estratégia de definição da nova identidade do movimento através da memória ${ }^{11}$. Müller ainda atesta a decisiva influência que Arthur Poerner e $O$ poder jovem tiveram nos folhetins e revistas surgidos de DCEs e CAs, nos anos 1980, remontando a história da UNE a partir das narrativas construídas pelo livro.

\section{Referências}

CARPEAUX, Otto Maria. História da participação política dos estudantes brasileiros. Revista Civilização Brasileira. No 19/20, p. 303. Rio de Janeiro, 1968.

CZAJKA, Rodrigo. A Revista Civilização Brasileira: Projeto Editorial e Resistência Cultural (1965-1968). Revista de Sociologia e Política, UFPR, Curitiba, v. 18, no 35, p. 95-117, fev. 2010.

CZAJKA, Rodrigo. Do Pessach ao Quarup ou os impasses ideológicos na literatura do pósgolpe. In: DURÃO, Fábio Alckcerud; MUSSI, Daniela; MARANHÃO, Andreia Pagani. (Orgs.). Marxismo: cultura e educação - contribuições do VII Colóquio Internacional Marx-Engels. $1^{\text {a }}$ ed. São Paulo: Nankin, p. 113-128, 2015.

DURHAM, E. R. O Ensino Superior no Brasil: Público e Privado. Disponível em: <http://nupps.usp.br/downloads/docs/dt0303.pdf>. Data de acesso: 05/10/2014.

\footnotetext{
${ }^{11}$ Müller faz referência a RICOEUR, Paul. La mémorie, l'histoire, l'oubli. Paris: Seuil, 2000.
} 
FORACCHI, Marialice. O Estudante e a Transformação da Sociedade Brasileira. São Paulo: Cia Editora Nacional, 1965.

GASPARI, Hélio. A Ditadura Envergonhada. São Paulo: Cia das Letras, 2002.

GUSSON, Claudia M. Movimento Estudantil e Repressão Judicial: o regime militar e a criminalização dos estudantes brasileiros (1964-1979). Dissertação (Mestrado) Departamento de História da Faculdade de Filosofia, Letras e Ciências Humanas da USP, São Paulo, 2008.

HAGEMEYER, Rafael. Movimento Estudantil 68: Imagens da Paixão. Dissertação (Mestrado) - Departamento de História da Universidade Federal do Paraná, Curitiba, 1997.

HALLEWELL, Laurence. O Livro no Brasil (Sua História). São Paulo: Edusp, 2012.

IANNI, O. Tipos e Mitos do Pensamento Brasileiro. Revista Sociologias, UFRG, Porto Alegre, ano 4, n. 7, p. 176-187, jan/jun, 2002.

KONDER, L. A Rebeldia, os Intelectuais e a Juventude. Revista Civilização Brasileira, n. $15,1967$.

KUCINSKI, Bernardo. Jornalistas e Revolucionários: Nos Tempos da Imprensa Alternativa. $2^{a}$ ed. São Paulo: Edusp, 2001.

MACHADO, Ana Maria. Da Resistência à Transição: A Literatura na Encruzilhada. In. SOSNOWSKI, Saúl; SCHWARTZ, Jorge (orgs.). Brasil: O Trânsito da Memória. São Paulo: Edusp, 1994.

MAIA, Nilton. Bomba da polícia assassina os sonhos de Zeca. Folha da Semana. Rio de Janeiro, p. 16, 25 de dez. a $1^{\circ}$ de jan. de 1965).

MARTINS FILHO, João Roberto. O Movimento Estudantil e a Militarização do Estado no Brasil (1964-1968). Tese (Mestrado) - Departamento de Ciências Sociais do Instituto de Filosofia e Ciências Humanas da Universidade de Campinas, Campinas, 1986.

MAUÉS, Flamarion. Livros Contra a Ditadura: Editoras de Oposição no Brasil, 19741984. São Paulo: Publisher Brasil, 2013.

MÜLLER, Angélica. A Resistência do Movimento Estudantil Brasileiro contra o Regime Ditatorial e o Retorno da UNE à Cena Pública (1969-1979). Tese (Doutorado) - Faculdade de Filosofia, Letras e Ciências Humanas da USP e Centre d'Histoire Sociale du XXème Siècle de l'Université de Paris 1. São Paulo, 2010.

NAPOLITANO, Marcos. Coração Civil: Arte, Resistência e Lutas Culturais Durante o Regime Militar Brasileiro (1964-1980). Tese (Livre-docência) - Departamento de História da Faculdade de Filosofia, Letras e Ciências Humanas da USP. São Paulo, 2011.

OLIVEIRA, João Alberto Saldanha de. A UNE e o Mito do Poder Jovem. Maceió: EDUFAL, 2005. 
POERNER, Arthur José. O Poder Jovem - história da participação política dos estudantes brasileiros. $2^{\mathrm{a}}$ ed. Rio de Janeiro: Civilização Brasileira, 1979.

REIMÃO, Sandra. Repressão e Resistência: Censura a Livros na Ditadura Militar. São Paulo: Edusp, Fapesp, 2011.

REIS FILHO, Daniel Aarão. 1968: O Curto Ano de Todos os Desejos. In: Tempo Social Revista de Sociologia da USP, São Paulo, v. 10, nº 2, out. 1998.

REIS FILHO, Daniel Aarão. A Revolução Faltou ao Encontro: os comunistas no Brasil. São Paulo: Brasiliense, 1990.

RIDENTI, Marcelo. Artistas e Intelectuais no Brasil Pós-1960. Revista Tempo Social. Revista de Sociologia da USP. São Paulo, v. 17, nº 1, p. 81-110, 2005.

RIDENTI, Marcelo. Em busca do Povo Brasileiro: Artista da Revolução, do CPC à Era da TV. Rio de Janeiro: Record, 2000.

RIDENTI, Marcelo. O Fantasma da Revolução Brasileira. São Paulo: Ed. Unesp, 1993.

RODRIGUES, Mavi. Michel Foucault Sem Espelhos: Um Pensador Proto Pós-Moderno. 2006. 237 f. Tese (Doutorado em Serviço Social) - Escola de Serviço Social da Universidade Federal do Rio de Janeiro, Rio de Janeiro, 2006.

SANTANA, Flávia de Angelis. Atuação Política do Movimento Estudantil no Brasil: 1964 a 1984. Dissertação (Mestrado) - Departamento de História da Faculdade de Filosofia, Letras e Ciências Humanas da USP, São Paulo, 2007.

SEGANFREDO, Sonia. UNE: instrumento de subversão. Rio de Janeiro: GRD, 1963.

Recebido em setembro de 2018

Aprovado em novembro de 2018 